Mr. R. H. FrankLIN: The striking thing about these cases to my mind is that some of them are too advanced for surgery. I think the condition of the seminal vesicle may have some bearing on the issue. If the vesicle is involved I think it unwise to do any operation.

Prof. AIrd: I agree.

Mr. Selwyn TAylor: If surgery is decided upon I believe that it should be radical in this type of case. In his Presidential Address to the Urological Section of the Royal Society of Medicine in I939, Mr. Everidge reported how he had collected results of a number of London hospitals where unilateral nephrectomy had been performed for tuberculosis. He found that when the lower end of the ureter had been left behind, a number of the patients had a stagnant collection of pus in the lower end of the ureter from which they became reinfected. He made a good case for the operation of nephro-ureterectomy. I feel fairly sure that this patient has tuberculosis of the contralateral renal tract.

MR. O. DANIEL: It has been our routine practice to remove the ureter only to about the level of the pelvic brim, not to follow it right down to the bladder. I believe that the number of cases in which trouble can be attributed to what is left is somewhat less than 5 per cent., and if trouble does develop, removal of the stump of ureter can then be performed.

PROF. AIRD: I am sorry to hear Mr. Daniel say that he only removes the ureter to the pelvic brim. There are some quarters where complete nephroureterectomy has been done for 25 years and it has been my own practice.

Dr. A. Pearse: We had a specimen about two years ago consisting of a length of ureter which was tuberculous, the kidney and upper part of the ureter having been removed previously. I do not remember what happened to that case.
Mr. O. DANIEL: That was from a woman who had a nephrectomy but continued to suffer from cystitis. Following removal of the stump of the ureter on that side the symptoms completely disappeared.

Prof. AIRD: Mr. Daniel said in only 5 per cent. of nephrectomies for tuberculosis are later symptoms attributable to the stump of ureter remaining behind. We have mentioned before that if you follow up all patients who have had nephrectomies performed for disease (stones, tuberculosis, tumour) relatively few of them are still alive after five years. How many who have tuberculous kidneys removed survive more than five years?

I am sure that the mortality rate would be much less if we kept these patients in our teaching hospitals for nephrectomy. Tissue immunity to tuberculosis is remarkable. People who get urogenital tuberculosis do not get bone tuberculosis, while people with bone tuberculosis do not as a rule get urogenital tuberculosis.

Mr. R. Shackman: Another aspect of this problem is the prognosis of genito-urinary tuberculosis in the male as compared with the female. The prognosis is undoubtedly worse in the male because of the secondary development of tubercue losis in the genital apparatus. There seems to be no corresponding involvement in the female, the ovaries and the tubes not being involved in genito urinary tuberculosis nearly so frequently as the corresponding organs in the male. There must be some local anatomical arrangement to account for this peculiar circumstance. The survival figures for renal tuberculosis in the male are about 40 per cent., which is poor.

Mr. O. Daniel: I believe that the tubes and ovaries are quite susceptible to tuberculosis, and many when removed for chronic inflammatory disease are found histologically to be tuberculous

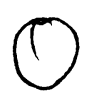

\title{
Case 2: Carcinomatous Ulcer of the Stomach
}

Case History (Mr. C. L. N. Robinson)

One year before admission the patient, a bar cellarman of 55 , had a haematemesis and melaena of one pint of blood. He was treated in Dulwich Hospital.

Eight months before admission he became short of breath on exertion, had palpitations and felt run down. He came to the outpatient department where blood studies revealed a normocytic anaemia. He was treated with ferrous sulphate. He improved on this but had lost one stone in weight and had pain in the chest after exertion. A barium meal showed a filling defect in the stomach.

On admission to hospital, physical examination revealed nothing of note. There were no abdominal or rectal masses, and the liver was not clinically enlarged. 
Laboratory investigations showed occult blood present in stools; W.B.C. 20,000 , with polymorphonucleocytosis; Hb. 92 per cent.; corrected B.S.R. $15 \mathrm{~mm} / \mathrm{hr}$. The blood chemistry was normal.

Gastroscopy showed a nodular growth in the upper third of the body of the stomach causing a pseudo hour-glass appearance.

Operation. On December 20, 1949, Professor Aird explored the abdomen through a thoracoabdominal approach and found a large indurated ulcer high on the lesser curvature of the stomach. The whole of the proximal part of the stomach was removed, leaving only a small portion of the pyloric antrum which was brought up and anastomosed to the oesophagus in the chest.

The postoperative course was stormy being complicated by bronchitis, and by thrombophlebitis in the left leg. The patient eventually made a good recovery.

\section{Pathology (Professor Dible)}

The specimen removed at operation showed a large ulcer on the lesser curvature of about $\frac{3}{4}$ "by I", which was extending on to the anterior wall of the stomach. On histological examination the whole area was found to be extensively infiltrated with adeno-carcinoma of an undifferentiated type. The muscle of the stomach wall ended abruptly at the edges of the malignant ulcer, the floor of which consisted of fibrous stroma everywhere infiltrated with carcinoma cells. Two lymphatic glands were embedded in the base of the ulcer-both of which were invaded.

The question of the superimposition of malignancy on a pre-existing ulcer having been raised, it remains to say that no positive histological evidence of this was to be found. The relatively short clinical history is against this supposition and whereas it is impossible to deny that a simple ulcer might have existed and all trace of simple inflammatory reaction of fibrosis have been obscured by the wide malignant invasion, the fact remains that no such simple inflammatory tissue was anywhere demonstrable. The interruption of the muscle was complete, but it was replaced everywhere by malignant stromal tissue, and although one artery showed a condition of obliterative endarteritis this occurred at a site where muscle was in existence and being invaded by malignant tissue. Although the history was short for a typical ulcer-cancer sequence it was long enough for one to expect extensive destruction of the gastric wall by malignant disease, such as was found.

\section{Discussion}

Mr. EwING: One interesting point is the comparatively long history of the case. He was admitted to another hospital a year ago with haematemesis and melaena. He was investigated eight months ago, yet at the time of admission to this hospital his $\mathrm{Hb}$. was 92 per cent. Professor Wilkie in diagnosis of cancer from simple peptic ulcer was led to think of diagnosis in terms of malignancy if $(x)$ there was rigidity and tenderness, and (2) if there was a high white cell count.

Prof. AIRD: Everything would conspire to suggest that there had been previous ulceration present if it were not for the actual site of the ulcer here.

Prof. Dible: There is no histological evidence of previous ulceration. There is a big lesion which has been there for some time, so that it is conceivable that if there were areas of simple ulcer they might now be infiltrated by cancer. This is not really a typical history found in proved cases of ulcer-cancer. Many cases known to me have had gastric trouble for 20 years.

Prof. AIrd: By a long history Mr. Ewing meant a history longer than the average cancer, but it would not begin to compete with the cancer superimposed on an old chronic ulcer. I am sorry that I did not do a total gastrectomy in this case. Had we taken more stomach away we could have removed a part of the pancreas, together with some of the lymph glands in relation to its upper border. Furthermore, the bit of stomach left may give just enough regurgitation of strong digestive juices for there to be more risk of peptic ulceration of the oesophagus now than there would have been if we had brought up the jejunum.

Mr. Shackman: Do X-ray and gastroscopy appearances of hour-glass stomach have much significance in the pre-operative diagnosis?

Prof. AIRD: I think they have. This certainly showed an early form of what I would say might be termed a malignant hour-glass. It is too high for the hour-glass associated with peptic ulcer. The diagnosis of carcinoma was very precisely made before operation, both by the radiologist and by Mr. Robinson who did the gastroscopy.

DR. LenNox: The pathologist who first examined this ulcer did think that ulcer cancer was fairly possible. At least it is an indication of the difficulties pathologists have had in the diagnosis of ulcer cancer for many years.

Mr. Selwyn TaYlor: How can we diagnose these cases earlier? It seems that barium meal examination is the most important single investigation which we can carry out. How can we, perhaps, obtain barium meal examinations more easily and less expensively? I think that since we have had mass radiography for demonstrating pulmonary tubercle, why not mass radiography for gastric cases? 
Prof. AIRD: That diagnosis was not made was not the patient's fault, for he had a haematemesis a year ago. I think really that haematemesis should be regarded in all cases very much more surgically. I think such cases should be afforded exploration on much more slender grounds than they are now.

Mr. EwING: I think the dividends are very small in the chance of being able to diagnose this in its early stages by early X-rays. A gastroenterologist at the Mayo Clinic investigated physicians and surgeons who came to his clinic with carcinoma of the stomach. The proportion of those who came at a stage when they were inoperable was the same as those who came earlier.

Prof. AIRD: Medical men are poor patients. A surgeon who recently died of carcinoma of the stomach had himself signs which he would at once have recognized in a patient. On X-ray he had a small filling defect but he refused to believe that it was a filling defect. He refused after operation to accept a diagnosis of carcinoma of the stomach.

Mr. Galbraith asked if the patient had any previous history of dyspepsia whatever. He thought that haematemesis should suggest the possibility of malignancy in a man of 55 . Professor Aird agreed.

Mr. McKeown: The problem of early diagnosis of carcinoma of the stomach is most difficult, and I think the only hope for people with carcinoma of the stomach is (i) early diagnosis, and (ii) radical surgery. At this operation (at which I assisted) access with an abdomino-thoracic approach was first-class.

Prof. AIRD: That has passed through my own mind and I have spoken of it before. A good many people are thinking along these lines now, notably Dr. Brunschwig. He is proceeding now to total gastrectomy and extensive pancreatectomy for the treatment of cancers of the stomach. People at the Royal Cancer Hospital are thinking in the same sort of way, and most of us are coming towards a similar view. The operation for cancer of the stomach, which should be done with a relative degree of safety, would include the removal of the whole stomach and great omentum together with part of the pancreas in order to remove the glands along its upper border. Ellison, Brunschwig and others have pointed out that total gastrectomy performed in this way through the chest is an easier operation than a high partial § resection.

Prof. Dible: (I) Does this operation take $\stackrel{\mathbb{D}}{\stackrel{2}{ }}$ no notice of where the cancer is ? (2) Do patients with cancer of the stomach die from their liver secondaries?

Prof. AIrD: As we see them clinically, patients who have recurrences after removal of the stomach for cancer have great masses in their upper abdomen which are really glandular. Recurrence in the part of the stomach left is quite rare. It is still not known what proportion have liver deposits.

MR. EwING: With radical operation for cancer of the breast the only discomfort is a scar, but in this operation (I) the patient must survive operation, (2) you must have a high enough dividend of people saved from death in order to justify what may be a very distressing post-operative course. Professor Holst in his radical resection for growths of the cardia felt that the low percentage of survivals and the high percentage of very distressing symptoms after operation made him wonder if it were justified. The symptoms were failure to gain weight, distaste for food, weakness, inability to return to work and anaemia.

Prof. AIRD: Some of the symptoms are indeed unfortunate, especially the regurgitation of bile.

Mr. SELWYN TAYLOR: Unless our diagnost methods improve we shall not see many patientf who are fit for this operation. The present type of patient we receive is usually only suitable for a palliative operation.

PROF. AIRD: I am not sure that I agree. I have been impressed with the apparently equal effects of the two operations. I do not think the difference should be very great. I think a man should be better after having his chest opened and the performance of this operation than after the pulling on the oesophagus which accompanies a partial gastrectomy. My mind is quite open about it however.

Mr. SELWYN TAYLOR: It is difficult to maintain weight after total gastrectomy and these patients do lose some of the joy of living. A partial gastrectomy may allow them a little more of this.

PROF. AIRD: I would be inclined to agree with $\frac{7}{2}$ Sir David Wilkie who said that when he had a radical operation he wanted all the potential sites $ᄋ$ of cancer to be removed even if he did not sur- $N$ vive. He only wanted to survive if he had a high N chance of non-recurrence of the disease. 